\title{
Compliance with noninvasive home ventilation in children with obstructive sleep apnoea
}

Anna Marie $\underline{\text { Nathan }}^{1}$, MrCPCH, Jenny Poh Lin $\underline{T a n g}^{2}$, MMed, FRCPCH, Anne $\underline{G o h}^{3}$, MMed, Oon Hoe $\underline{T e o h}^{3}$, MMed, MRCPCH, Oh Moh $\underline{\mathrm{Chay}^{3}}$, MMed, FRCPCH

INTRODUCTION This study aimed to determine compliance with noninvasive home ventilation in children with obstructive sleep apnoea and the factors affecting this compliance.

METHODS We retrospectively reviewed 51 children who were prescribed noninvasive home ventilation for the management of obstructive sleep apnoea from 1 January 2000 until 31 May 2008. Noninvasive ventilation was started based on positive polysomnogram, i.e. obstructive apnoea hypopnea index $\geq 1 / \mathrm{hr}$. Compliance was defined as the use of noninvasive ventilation $\geq 4$ days/week.

RESULTS Noninvasive home ventilation was started at a median age of 11.5 years. In all, 21 (41.2 \%) children were reported to be compliant with treatment. Univariate analysis revealed that the female gender $(p=0.017)$, presence of asthma $(p=0.023)$, presence of genetic syndromes $(p=0.023)$, use of bi-level ventilation versus continuous positive airway pressure $(p=0.027)$, and funding from the social work department $(p=0.049)$ were associated with compliance with noninvasive home ventilation. Logistic regression revealed the presence of asthma $(p=0.008)$ and female gender $(p=0.047)$ to be significantly associated with compliance with treatment. However, factors such as counselling prior to initiation of treatment, severity of obstructive sleep apnoea before initiation of treatment, obesity, use of humidification, and polysomnogram indices were not found to be associated with treatment compliance. CONCLUSION Only $41.2 \%$ of the children in this study were reported to be compliant with noninvasive home ventilation. The female gender and the presence of asthma were associated with treatment compliance. Future research focusing on effective methods to improve compliance with noninvasive home ventilation in children should be undertaken.

Keywords: children, compliance, continuous positive airway pressure, home ventilation, obstructive sleep apnoea

\section{INTRODUCTION}

Obstructive sleep apnoea is a significant cause of morbidity; it affects the central nervous system, as well as the cardiovascular, metabolic, endocrine and growth systems. ${ }^{(1)}$ In otherwise normal children with obstructive sleep apnoea, adenotonsillectomy is often the first treatment option. ${ }^{(2)}$ Studies have shown that up to $60 \%$ of children with obstructive sleep apnoea can be cured with adenotonsillectomy. ${ }^{(3)}$ However, in children with other comorbidities such as obesity, genetic or metabolic syndromes, and craniofacial abnormalities, adenotonsillectomy may not succeed in curing obstructive sleep apnoea.(4-6) As adenotonsillectomy is only successful in $33 \%-46 \%$ of obese children with obstructive sleep apnoea, there is an increasing need for noninvasive ventilation in this group of children. ${ }^{(7,8)}$

Since the advent of noninvasive ventilation via a facemask interface in the 1980s for adults with obstructive sleep apnoea, noninvasive ventilation is recognised as an effective treatment of obstructive sleep apnoea in children as young as 2 years old. ${ }^{(9)}$ Nevertheless, even though treatment of obstructive sleep apnoea is available and effective, the acceptance of, and compliance with, noninvasive home ventilation is not universal. ${ }^{(10)}$ Compliance with noninvasive home ventilation in adults has been reported to range from $46 \%$ to $76 \% .^{(11,12)}$
However, data on compliance with such treatment in children is lacking.

We hypothesise that compliance with noninvasive home ventilation is suboptimal in children with obstructive sleep apnoea. Thus, the aim of this study was to determine compliance with noninvasive home ventilation in children with obstructive sleep apnoea and the factors affecting this compliance.

\section{METHODS}

This was a retrospective study of cases of paediatric obstructive sleep apnoea in a tertiary hospital in Singapore from 1 January 2000 to 31 May 2008. Review of the case notes of these children took place from 1 February to 30 September 2008. We found 88 children who were started on noninvasive ventilation for various forms of sleep-related breathing disorders. However, only 51 of the 88 children were included in this study because the case notes of 12 children were not available, 2 children died before commencement of noninvasive ventilation, 2 had just started on treatment for less than six months, and 21 were started on treatment for reasons other than obstructive sleep apnoea (e.g. alveolar hypoventilation syndromes). These 51 children with symptoms of obstructive sleep apnoea were referred to paediatric

\footnotetext{
${ }^{1}$ Department of Paediatrics, University Malaya Medical Centre, Kuala Lumpur, Malaysia, ${ }^{2}$ Asthma, Lung, Sleep and Allergy Centre, Gleneagles Medical Centre, ${ }^{3}$ Respiratory Medicine Service, Department of Paediatrics, KK Women's and Children's Hospital, Singapore

Correspondence: Dr Jenny Tang PL, Consultant Paediatrician, Asthma, Lung, Sleep and Allergy Centre, Gleneagles Medical Centre, 6 Napier Road, Singapore 258499. jenny.tang.pl@gmail.com
} 
respiratory specialists. Ethics approval for this study was obtained from the local ethics committee, and patient confidentiality was maintained.

Children with symptoms of obstructive sleep apnoea underwent fully attended, baseline polysomnogram before surgery. A repeat polysomnogram was performed after surgery if the child still had habitual snoring postoperatively and/or moderate-severe obstructive sleep apnoea before surgery. All polysomnograms were scored by a trained sleep technician and a paediatric respiratory physician, according to accepted paediatric standards. ${ }^{(13)}$ Obstructive apnoea was defined as $\mathrm{a} \geq 90 \%$ decrease in airflow that lasts for at least two breath cycles. Hypopnoea was defined as a $\geq 50 \%$ decrease in airflow associated with $\geq 3 \%$ desaturation and/or arousal, lasting for at least two breath cycles. Central apnoea was defined as the absence of airflow, and chest and abdominal excursions lasting for either $\geq 20 \mathrm{~s}$ or at least two breath cycles, associated with an arousal or desaturation of $\geq 3 \%$. A diagnosis of obstructive sleep apnoea was made if the obstructive apnoea hypopnoea index (OAHI) was $\geq 1 / \mathrm{hr}$. The varying degrees of obstructive sleep apnoea are defined as follows: (a) mild $-\mathrm{OAHI}=1-5 / \mathrm{hr}$; (b) moderate $-\mathrm{OAHI}=6-9 / \mathrm{hr}$; and (c) severe $-\mathrm{OAHI} \geq 10 / \mathrm{hr}$.

Children who had a positive polysomnogram with the presence of Brodsky ${ }^{(14)}$ grade $2+$ tonsils and/or adenoids were referred for adenotonsillectomy. Children who had either obstructive sleep apnoea that did not warrant surgical intervention or a positive polysomnogram after surgical intervention were prescribed noninvasive home ventilation. Most of these children underwent a continuous positive airway pressure/bi-level positive airway pressure titration study to determine the ideal ventilator pressure for each child. Initial weight, height and blood pressure were taken at either the child's first admission to hospital (during the polysomnogram) or the first clinic visit. Hypertension was defined as a blood pressure above the 95th percentile for age, height and sex. ${ }^{(15)}$ Obesity was defined as a body mass index above the 95th percentile for sex, based on available local data. ${ }^{(16)}$

Information on the children's compliance with noninvasive ventilation and the side effects experienced were obtained via a review of the case notes. Compliance was defined as the reported use of noninvasive ventilation for $\geq 4$ days/week. Noninvasive ventilation educational services have been available at our hospital from 31 October 2006 and these services are made available at the initiation of treatment. During these educational sessions, both children and their parents watched a 15-min video on obstructive sleep apnoea and how noninvasive ventilation works. Subsequently, the children were mask fitted and put on a designated continuous positive airway pressure/bi-level positive airway pressure machine for 20 mins in a darkened room; empirical settings were prescribed by the managing physician. In our hospital, children with obstructive sleep apnoea not compliant with noninvasive home ventilation and all infants were prescribed humidifiers. Parents were given the contact information of suitable vendors that were able to supply them with the machine and mask.

Data was analysed using the Statistical Package for the Social Sciences version 14.0 (SPSS Inc, Chicago, IL, USA). Descriptive analysis of all the aforementioned 51 children prescribed noninvasive ventilation was performed. Mann-Whitney $U$ test was used to determine the differences between the polysomnogram indices of children compliant with treatment and those who were not. Wilcoxon rank test was used to compare the differences in the polysomnogram indices: (a) before adenotonsillectomy vs. after adenotonsillectomy; and (b) before continuous positive airway pressure support vs. on continuous positive airway pressure support. Factors that could be associated with compliance with noninvasive ventilation were compared using chi-square and Fisher's exact tests, where appropriate. Logistic regression analysis was used to determine significant factors affecting compliance with noninvasive ventilation. A p-value of $<0.05$ was considered statistically significant.

\section{RESULTS}

Data on the 51 children were analysed. Demographic data of the children are shown in Table I. The most common complaints encountered during respiratory consultation are as follows: (a) snoring ( $n=48)$; (b) excessive daytime somnolence $(n=20)$; (c) restless sleep $(n=18)$; (d) poor school performance $(n=11)$; (e) nocturnal enuresis $(n=8)$; and ( $f$ ) morning headaches $(n=4)$.

The median body mass index of the 51 children was $25.3 \mathrm{~kg} / \mathrm{m}^{2}$ (interquartile range [IQR] 22.9, 35.2). Diabetes mellitus was present in $11(21.6 \%)$ children, and hypertension was detected in 16 of the $40(40.0 \%)$ children who had their blood pressure taken. Diabetes mellitus was found to be significantly associated with obesity ( $p=0.017$; odds ratio [OR] 10.00; 95\% confidence interval [CI] 1.17-85.59), but not with hypertension ( $p=0.295$; OR 2.28; 95\% Cl 0.55-9.36). In all, only 47 of the 51 children underwent fully attended polysomnogram; 2 children underwent overnight oximetry instead of a fully attended polysomnogram to confirm the diagnosis of obstructive sleep apnoea, and 2 had tonsillectomies before a poly-somnogram was done. The (preintervention) polysomnogram parameters at diagnosis for the 47 children were as follows: (a) median OAHI - 26.7/hr (IQR 12.0, 79.7); (b) median respiratory disturbance index (RDI) - 28.0/hr (IQR 12.2, 77.3); (c) median oxygen nadir - 74\% (IQR 50, 83); (d) median arousal index - 13.8/hr (IQR 6.3, 30.3); and (e) median rapid eye movement (REM) RDI - 59.8/hr (IQR 25.7, 89.6).

Of the 51 children, 36 (70.6\%) underwent adenotonsillectomy. None had an adenoidectomy alone, and two refused adenotonsillectomy. After adenotonsillectomy, there were significant improvements in RDI $(z=-2.89, p=0.004)$, OAHI $(z=-2.74, p=0.006)$, oxygen nadir $(z=-3.03, p=0.002)$, 
Table I. Demographic characteristics of the children $(n=51)$ prescribed noninvasive home ventilation.

\begin{tabular}{lc}
\hline Characteristic & No. (\%) \\
& \\
\hline Age at treatment* (yrs) & $11(8,13)$ \\
Gender & \\
Male & $36(70.6)$ \\
Female & $15(29.4)$ \\
Ethnicity & \\
Chinese & $33(64.7)$ \\
Malay & $13(25.5)$ \\
Indian & $3(5.9)$ \\
Others & $2(3.9)$ \\
Comorbid conditions & \\
Obesity & $21(41.2)$ \\
Asthma & $9(17.6)$ \\
Allergic rhinitis & $36(70.6)$ \\
Large tonsils/adenoids & $31(60.8)$ \\
Comorbid diseases & \\
Association with syndromes ${ }^{\dagger}$ & $13(25.5)$ \\
Neurodevelopmental delay ${ }^{\dagger}$ & $11(21.6)$ \\
Chronic lung disease & $2(3.9)$ \\
Cardiovascular disease & $5(9.8)$ \\
Neuromuscular disease & $3(5.9)$ \\
Total & $34(66.7)$ \\
Type of NIV prescribed & \\
CPAP (auto/manual) & $47(92.2)$ \\
BiPAP & $4(7.8)$ \\
Use of humidifier & $18(35.3)$ \\
Underwent CPAP counselling & $22(43.1)$ \\
Underwent CPAP titration & $37(72.5)$ \\
Funding & \\
MSW/charity & $22(45.8)$ \\
Self-sponsored & $26(54.2)$ \\
\hline Da presente as & \\
\hline
\end{tabular}

${ }^{*}$ Data presented as median (interquartile range). ${ }^{\dagger}$ Syndromes such as Down, Kabuki, incontinentia pigmenti, CATCH 22, Pierre Robin, and Goldenhar. ${ }^{\ddagger}$ Neurodevelopmental delay such as those due to autism and other unknown causes of developmental delay. ${ }^{\S}$ Funding for noninvasive ventilation treatment could not be determined in three children. Therefore, the percentages in this category were calculated using a sample size of 48 .

BiPAP: bi-level positive airway pressure; CPAP: continuous positive airway pressure; MSW: medical social worker; NIV: noninvasive ventilation

arousal index $(z=-2.33, p=0.020)$ and REM RDI $(z=-2.90$, $\mathrm{p}=0.004)$. However, polysomnogram results before and after surgery were available for only 12 of the 23 obese children who underwent adenotonsillectomy. In these 12 children, significant improvements in RDI $(z=-2.22, p=0.026)$, OAHI $(z=-2.13$, $\mathrm{p}=0.033)$, oxygen nadir $(z=-2.36, p=0.018)$ and REM RDI $(z=-2.03, p=0.043)$, were noted after surgical intervention. No significant improvement was observed for arousal index $(z=-1.68, p=0.093)$

Continuous positive airway pressure/bi-level positive airway pressure titration to determine ideal ventilator pressures were performed for $37(72.5 \%)$ children. The mean airway pressure used was 8 (range 4-16) $\mathrm{cmH}_{2} \mathrm{O}$. During titration studies, the use of noninvasive ventilation resulted in significant improvements in OAHI $(z=-5.18, p<0.001)$, RDI $(z=-5.81, p<0.001)$, oxygen nadir $(z=-5.28, p<0.001)$, REM RDI $(z=-5.22$, $p<0.001)$ and arousal index $(z=-3.57, p<0.001)$. In accordance with the American Association of Sleep Medicine titration guidelines, 37 (72.5\%) children had adequate to optimal titration studies performed. ${ }^{(17)}$ Only 21 (41.2\%) children were reported to be compliant with noninvasive ventilation. The most common reasons for noncompliance (information was available for 46 patients) were patient refusal $(n=25)$ and side effects $(n=9)$, especially nasal symptoms and the feeling of suffocation. In all, 8 (15.7\%) children/parents immediately refused treatment when the need for noninvasive ventilation was suggested; 5 (9.8\%) parents felt the treatment was unnecessary, $2(3.9 \%)$ felt the treatment was inconvenient, and $1(2.0 \%)$ thought it was expensive.

Univariate analysis revealed associations between compliance with noninvasive ventilation and factors such as the female gender, presence of comorbid conditions (i.e. asthma and genetic disease), use of bi-level positive airway pressure, and monetary assistance (from the social work department in purchasing the machine) (Table II).

Logistic regression analysis revealed that only the presence of asthma and female gender were significantly associated with compliance with noninvasive ventilation (Table II). Symptomatic children, such as those presenting with complaints of excessive daytime sleepiness ( $p=0.891$, OR 1.05, 95\% Cl 0.53-2.07), restless sleep $(p=1.00$, OR 1.00,95\% Cl 0.49-2.01) or poor school performance $(p=0.165$, OR $0.55,95 \% \mathrm{Cl} 0.29-1.02)$, were not found to be more compliant with noninvasive ventilation than those who were asymptomatic. In our study, there was no significant difference between the polysomnogram indices (before institution of noninvasive ventilation) of the children who were compliant with treatment and those who were not compliant (Table III). Acceptability of continuous positive airway pressure titration studies, as graded by the American Association of Sleep Medicine, ${ }^{(17)}$ was also not associated with treatment compliance $(p=0.53)$.

\section{DISCUSSION}

In the present study, less than half (41.2\%) of the children were reported to be compliant with noninvasive ventilation - lower than that reported in adults. ${ }^{(11,12)} \mathrm{A}$ randomised, controlled, doubleblind study by Marcus et $\mathrm{al}^{(10)}$ that looked at compliance rates in children undergoing continuous positive airway pressure versus those undergoing bi-level positive airway pressure demonstrated that even in a trial situation where the support was intensive and the equipment was free, $27 \%$ of children dropped out of the study. There was no difference between the compliance rates of children who underwent bi-level positive airway pressure and those who underwent continuous positive airway pressure. ${ }^{(10)}$

The present study provides evidence that the greatest challenge in treating obstructive sleep apnoea in children is poor compliance with noninvasive home ventilation. Determinants of noninvasive ventilation compliance may be categorised into the following factors: (a) patient/parent; (b) disease-related; and (c) equipment-related. Patient factors that influence compliance, especially among older children, are motivation, 
Table II. Comparison of factors that could affect compliance with noninvasive home ventilation in children.

\begin{tabular}{|c|c|c|c|c|c|c|}
\hline \multirow[t]{2}{*}{ Variable } & \multicolumn{2}{|c|}{ No. of children (\%) } & \multirow{2}{*}{$\begin{array}{l}\text { Univariate } \\
\text { p-value }\end{array}$} & \multirow[t]{2}{*}{ OR $(95 \% \mathrm{Cl})$} & \multirow{2}{*}{$\begin{array}{l}\text { Logistic } \\
\text { regression } \\
\text { p-value }\end{array}$} & \multirow{2}{*}{$\begin{array}{l}\text { Adjusted OR } \\
(95 \% \mathrm{CI})\end{array}$} \\
\hline & $\begin{array}{c}\text { Compliant } \\
(n=21)\end{array}$ & $\begin{array}{l}\text { Noncompliant } \\
\quad(n=30)\end{array}$ & & & & \\
\hline Age group (yrs) & & & 0.759 & NA & NA & NA \\
\hline$<1$ & $2(9.5)$ & $1(3.3)$ & & & & \\
\hline $1-6$ & $2(9.5)$ & $4(13.3)$ & & & & \\
\hline $6-12$ & $8(38.1)$ & $16(53.3)$ & & & & \\
\hline$>12$ & 9 (42.9) & $9(30.0)$ & & & & \\
\hline Gender & & & 0.017 & $2.10(0.99-4.40)$ & $0.047^{+}$ & $5.22(1.02-26.77)$ \\
\hline Male & $11(52.4)$ & 25 (83.3) & & & & \\
\hline Female & $10(47.6)$ & $5(16.7)$ & & & & \\
\hline \multicolumn{7}{|l|}{ Comorbidity* } \\
\hline Obesity & $11(52.4)$ & 19 (63.3) & 0.434 & $0.83(0.51-1.35)$ & NA & NA \\
\hline Allergic rhinitis & $15(71.4)$ & $22(73.3)$ & 0.607 & $0.73(0.22-2.45)$ & NA & NA \\
\hline Asthma & 7 (33.3) & $2(6.7)$ & $0.023^{*}$ & $3.00(0.87-10.3)$ & $0.008^{+}$ & $15.9(2.08-122.4)$ \\
\hline Genetic syndrome & 7 (33.3) & $2(6.7)$ & $0.023^{*}$ & $3.00(0.87-10.3)$ & 0.255 & $3.36(0.42-27.0)$ \\
\hline Severity of OSA & & & 0.859 & NA & NA & NA \\
\hline Mild & $3(14.3)$ & $6(20.0)$ & & & & \\
\hline Moderate & $5(23.8)$ & $6(20.0)$ & & & & \\
\hline Severe ${ }^{\S}$ & $13(61.9)$ & $18(60.0)$ & & & & \\
\hline Ventilation & & & $0.027^{*}$ & $3.60(2.39-5.10)$ & 0.831 & $1.38(0.7-26.9)$ \\
\hline CPAP (manual/auto) & $17(81.0)$ & $30(100.0)$ & & & & \\
\hline BiPAP & $4(19.0)$ & $0(0.0)$ & & & & \\
\hline Humidifier & 9 (42.9) & $8(26.7)$ & 0.227 & $1.50(0.85-1.37)$ & NA & NA \\
\hline CPAP/BiPAP titration & $16(76.2)$ & $23(76.7)$ & $1.00^{*}$ & $0.99(0.57-1.71)$ & NA & NA \\
\hline CPAP counselling & $8(38.1)$ & $14(46.7)$ & 0.543 & $0.87(0.55-1.37)$ & NA & NA \\
\hline Funding by MSW/charity & $13(61.9)$ & $9(30.0)$ & 0.049 & $1.69(0.96-2.97)$ & 0.192 & $2.90(0.59-14.35)$ \\
\hline
\end{tabular}

${ }^{*}$ Fisher's exact test. ${ }^{\dagger} \mathrm{p}$-value was statistically significant in logistic regression analysis. ${ }^{\ddagger}$ Some patients had more than one comorbity. ${ }^{\S}$ One child with a positive overnight oximetry was classified as severe OSA.

BiPAP: bi-level positive airway pressure; CI: confidence interval; CPAP: continuous positive airway pressure; MSW: medical social worker; NA: not available; OR: odds ratio; OSA: obstructive sleep apnoea

Table III. Comparison of polysomnogram results (before initiation of noninvasive home ventilation) in children compliant and noncompliant with treatment.

\begin{tabular}{|c|c|c|c|c|}
\hline \multirow[t]{2}{*}{ Results } & \multicolumn{2}{|c|}{ Median (interquartile range) } & \multirow[t]{2}{*}{ z-score } & \multirow[t]{2}{*}{ p-value } \\
\hline & $\begin{array}{l}\text { Compliant } \\
(n=20)\end{array}$ & $\begin{array}{c}\text { Noncompliant } \\
(n=30)\end{array}$ & & \\
\hline $\operatorname{RDI}(n=50)$ & $25.1(7.3,60.5)$ & $13.0(7.9,29.6)$ & -0.891 & 0.373 \\
\hline Oxygen nadir ${ }^{\dagger}(n=50)$ & $76(54.8,85.8)$ & $81(62.8,86.0)$ & -0.41 & 0.685 \\
\hline Arousal index $(n=48)^{*}$ & $7.2(5.0,29.7)$ & $10.6(4.5,13.9)$ & -0.369 & 0.712 \\
\hline
\end{tabular}

${ }^{*}$ Polysomnogram results are not complete as some data is missing from both the compliant and noncompliant groups. ${ }^{\dagger}$ Data is presented as percentage. OAHI: obstructive apnoea hypopnoea index; RDI: respiratory distress index; REM: rapid eye movement

presence of side effects of the treatment, and the perceived impact of the disease on their life. ${ }^{(18,19)}$ In this study, logistic regression revealed that the female gender and the presence of asthma were significant factors affecting compliance with noninvasive ventilation. The female gender as a significant factor leading to better compliance with noninvasive ventilation has also been shown in adult studies, but this has not been consistently replicated. ${ }^{(20,21)}$ A lower level of motivation and lack of realisation of illness in males, as compared to females, may be related to this finding. Additionally, our study also found that children with asthma were more compliant with noninvasive ventilation. This novel finding can perhaps be explained by these children's increased contact with healthcare professionals who may emphasise the importance of compliance with medication and treatment.

The most common reasons for noncompliance in our study were patient refusal and the presence of side effects, especially nasal symptoms. This was also demonstrated in a study by Baltzan et al, which reported that the two common side effects, nasal congestion and mouth leak, were associated with poor compliance in adults. ${ }^{(22)}$ However, in our study, humidification (which has previously been shown to reduce nasal symptoms) and improved compliance with noninvasive ventilation were not associated. ${ }^{(23)}$ This may be because humidification is usually prescribed to children with poor compliance to treatment. Although education has been shown to play an important 
role in improving compliance with any form of treatment, ${ }^{(24)}$ noninvasive ventilation education did not improve treatment compliance in the present study. However, this may be because the educational service had only just started and not all children were counselled at treatment initiation. It has also been shown that early education and intensive follow-up that start within the first few weeks of initiation of noninvasive ventilation improve treatment compliance. ${ }^{(21,24)}$ Hence, perhaps in the management of children who need noninvasive ventilation, there should be a focus on intensive education and individualised support throughout the first few weeks of initiating noninvasive ventilation.

As our study is a retrospective one, data on compliance with noninvasive home ventilation was not formally assessed but was instead dependent on parental reports. This usually results in an overestimation of treatment compliance. The reliance on parental reports rather than on device memory is unavoidable as the required equipment (machines with inbuilt memory chips) is expensive and not subsidised by our local healthcare service, thus not all our patients may be able to afford it. Our study size was also small, which may have affected the power to detect statistically significant differences between the compliant and noncompliant patients. Nonetheless, this study has illustrated that treatment compliance is currently suboptimal and greater efforts are required to improve compliance.

In conclusion, only $41.2 \%$ of the children in the present study were compliant with noninvasive ventilation. Improved compliance with noninvasive ventilation was seen in female children and asthmatic children. In our study, noninvasive ventilation education, titration studies, humidification and severity of obstructive sleep apnoea did not significantly affect compliance. Patient refusal and side effects from noninvasive ventilation were the main causes of poor compliance. There is a need for future trials that look at the impact of desensitisation protocols, continuous positive airway pressure counselling and rigorous follow-up, with objective assessment of compliance with noninvasive home ventilation in children with obstructive sleep apnoea.

\section{ACKNOWLEDGEMENTS}

We would like to thank the dedicated staff of the paediatric respiratory and sleep laboratory at KK Women's and Children's Hospital, Singapore, for their help in obtaining some of the data, as well as for their support of the patients on noninvasive ventilation.

\section{REFERENCES}

1. Capdevila OS, Kheirandish-Gozal L, Dayyat E, Gozal D. Pediatric Obstructive Sleep Apnea: Complications, Management, and Long-term Outcomes. Proc Am Thorac Soc 2008; 5:274-82.
2. Guilleminault C, Huang YS, Glamann C, Li K, Chan A. Adenotonsillectomy and obstructive sleep apnea in children: a prospective survey. Otolaryngol Head Neck Surg 2007; 136:169-75.

3. Friedman M, Wilson M, Lin HC, Chang HW. Updated systematic review of tonsillectomy and adenoidectomy for treatment of pediatric obstructive sleep apnea/hypopnea syndrome. Otolaryngol Head Neck Surg 2009; 140:800-8.

4. Amonoo-Kuofi K, Phillips SP, Randhawa PS, et al. Adenotonsillectomy for sleep-disordered breathing in children with syndromic craniosynostosis. J Craniofac Surg 2009; 20:1978-80.

5. Costa DJ, Mitchell R. Adenotonsillectomy for obstructive sleep apnea in obese children: a meta-analysis. Otolaryngol Head Neck Surg. 2009; 140:455-60.

6. Nashed A, Al-Saleh S, Gibbons J, et al. Sleep-related breathing in children with mucopolysaccharidosis. J Inherit Metab Dis 2009; 32:544-50.

7. Mitchell RB, Kelly J. Adenotonsillectomy for obstructive sleep apnea in obese children. Otolaryngol Head Neck Surg 2004; 131:104-8.

8. Tang JP. Obesity and obstructive sleep apnoea hypopnoea syndrome in Singapore children. Ann Acad Med Singapore 2008; 37:710-4.

9. Marcus CL, Ward SL, Mallory GB, et al. Use of nasal continuous positive airway pressure as treatment of childhood obstructive sleep apnea. J Pediatr 1995; 127:88-94.

10. Marcus CL, Rosen G, Ward SL, et al. Adherence to and effectiveness of positive airway pressure therapy in children with obstructive sleep apnea. Pediatrics 2006; 117:e442-51.

11. Kribbs NB, Pack AI, Kline LR, et al. Objective measurement of patterns of nasal CPAP use by patients with obstructive sleep apnea. Am Rev Respir Dis 1993; 147:887-95.

12. Meslier N, Lebrun T, Grillier-Lanoir V, et al. A French survey of 3,225 patients treated with CPAP for obstructive sleep apnoea: benefits, tolerance, compliance and quality of life. Eur Respir J 1998; 12:185-92.

13. Iber C, Ancoli-Israel S, Chesson AL, eds. The AASM Manual for the Scoring of Sleep and Associated Events: Rules, terminology and technical specifications. Westchester, IL: American Academy of Sleep Medicine, 2007.

14. Brodsky L. Modern assessment of tonsils and adenoids. Pediatr Clin North Am 1989; 36:1551-69.

15. National High Blood Pressure Education Program Working Group on High Blood Pressure in Children and Adolescents. The fourth report on the diagnosis, evaluation, and treatment of high blood pressure in children and adolescents. Pediatrics 2004; 114:555-76.

16. Board SHP. Health Screening for Primary School [online]. Available at: htttp://www.hpb.goc.sg/HOPPortal/health-article/632. Accessed January 15, 2011.

17. Kushida CA, Chediak A, Berry RB, et al. Clinical Guidelines for the Manual Titration of Positive Airway Pressure in Patients with Obstructive Sleep Apnea. J Clin Sleep Med 2008; 4:157-71.

18. Stepnowsky CJ Jr, Marler MR, Ancoli-Israel S. Determinants of nasal CPAP compliance. Sleep Med 2002; 3:239-47.

19. Tyrrell J, Poulet C, Pe Pin JL, Veale D. A preliminary study of psychological factors affecting patients' acceptance of CPAP therapy for sleep apnoea syndrome. Sleep Med 2006; 7:375-9.

20.Sin DD, Mayers I, Man GC, Pawluk L. Long-term compliance rates to continuous positive airway pressure in obstructive sleep apnea: a population-based study. Chest 2002; 121:430-5.

21. Budhiraja R, Parthasarathy $S$, Drake $C L$, et al. Early CPAP use identifies subsequent adherence to CPAP therapy. Sleep 2007; 30:320-4.

22. Baltzan MA, Elkholi O, Wolkove N. Evidence of interrelated side effects with reduced compliance in patients treated with nasal continuous positive airway pressure. Sleep Med 2009; 10:198-205.

23. Massie CA, Hart RW, Peralez K, Richards GN. Effects of humidification on nasal symptoms and compliance in sleep apnea patients using continuous positive airway pressure. Chest 1999; 116:403-8.

24. Meurice JC, Ingrand P, Portier F, et al. A multicentre trial of education strategies at CPAP induction in the treatment of severe sleep apnoeahypopnoea syndrome. Sleep Med 2007; 8:37-42. 